way or other its action and its existence traceable to the sun. That there was an unlimited supply of energy in the interior of the earth was a circumstance which had, he said, been overlooked. In speaking of this energy, Mr. Milne first referred to that portion of it which crops out upon the surface in countries like Japan, Iceland, and New Zealand, in the form of hot springs, solfataras, volcanoes, \&c. He stated that there was an unlimited supply of water in hot springs within a radius of one hundred miles around Tokio, and that the heat of these springs could be converted into an electric current, and the energy trans. mitted to the town. The second part of the paper referred to the possibility of obtaining access to the heat which did not crop out in the surface.

THE whole behaviour of homogeneous colours is explained (according to Herr Albert, Wied. Ann., No. 5), on the YoungHelmholtz theory, by this assumption: To a lessening of the intensity of vari-coloured light correspond various lessening of the strength of sensation, such that for rays of less wave-length, to whatever part of the spectrum they belong, it decreases more slowly than for rays of greater wave-length.

\section{GEOGRAPHY IN RUSSIA}

THE just issued "Annual Report of the Russian Geographical Society for 188I" shows that during last year the Society has again accomplished a good deal of useful scientific work. A subject to which much attention was given was the establishment of polar meteorological stations. The station at Novaya Zemlya has already been in operation, as is known, for two years, and a new one, which will be established at the mouth of the Lena, is provided with the best instruments, and is intrusted to persons who will be able to make of it a first-class meteorological observatory. During the summer the expedition will reach the shores of the Arctic Ocean, and begin the meteorological observations. The Dutch station will be erected at Port Dickson, at the mouth of the Yenisei.

Among the scientific expeditions undertaken by the Society, that of M. Polakoff, to Sakhalin, promises to give very interesting results The rich ornithological collections made in the Alexandrovsk Valley, on the western coast, proved that the birds of Western Sakhalin have a remarkable likeness with those of Siberia and Northern Russia. The same is true with regard to the former inhabitants of Sakhalin, whose stone implements and remains of earthenware, discovered in great masses, are much like, or even identical to, those of European Russia ; the presence of obsidian implements, however, originally from Kamschatka, or from the islands of the Pacific, hints that the inhabitants were in intercourse with these countries. M. Polakkoff has also discovered dwellings of the same period, which were holes, like those of the Kamtchadales, the numerous stone pieces which were used to be attached to the nets, show that the nets of the prehistoric man were very large, and that fishing was carried on to a great extent at that period.

The result of M. Polakoff's explorations of the eastern shores of the island, as well as in its middle parte, are not yet known. M. Adrianoff's journey in very little known parts of the Tormsk and Sayan Mountains, during which the explorer crossed Lake Teletzekoye and the Shapshal Mountains, have given rich materials for the geology, zoology, and botany of these countries. The travels of A. E. Regel to the Pamir, M. Hedroitz's explorations of the alluvial deposits of the Amu-daria, M. Lessar's travel to Saraks, and M. Moushketoff's researches on Caucasus, have already been mentioned in NATURE.

A very interesting journey, mentioned in the "Report," was made by A. W. Eliseeff, who tried to follow the same route to Palestine which was followed by the Jews during their exode from Egypt. M. Eliseeff discovered during the journey numerous traces of man of the Palæolithic and of the Neolithic periods in Arab:a Petrea, as well as in Egypt and in Palestine. The prehistoric man of the Sinai peninsula belonged to two different types : one, with light bones, of the Semitic type, and the other, with massive bones, of the Berber type; dolichocephalic skulls are predominant. Both had the custom of burning corpses, and did not neglect anthropophagy ; however, their chief food consisted of wild animals, fishes, and molluscs. The disposition of these remains confirms the hypothesis of Owen, that the Sinai peninsular and lower. Egypt were under water, excepting the higher terraces, after man inhabited the banks of the Nile. As to the present inhabitants, the Arabs of the peninsula afford two different types: a western one, more akin to the Fellah and
Egyptian type, and the eastern one, which is of a purer Arabian origin. The nomad Bedouins belong to different sub-types, and there are in the Bedouin desert, traces of a fair-haired people, as well as representatives of Berberian and Ethiopian blood. Some very interesting material for a knowledse of prehistonit man was also discovered by M. W. Malakhoff, during his journey on the western slopes of the Middle Ural. The remains of this epoch are very numerous, especially on the shores of lakes, and they are the more interesting, as we find here the first vestiges of an epoch when the Neolithic man began to discover the properties of metals, and to manufacture metallic implements from the rich ores he found on the Ural. The skeletons of men of this period discovered, together with mixed implements of stone, bone, and copper, are most interesting, especially with regard to the skulls, which represent a very low stage of human development. The remains of a later epcch (implements and rock hieroglyphics) are also very numerons. M. Malakhoff concluded his researches by ethnographical observations on the present Permyaks, whom he considers as very nearly akin to the primary prehistoric inhabitants of this region. G. N. Potanin's exploration of the Votyaks, of their migrations, mythology, and customs, and an excursion of S. K. Kouznetzoff to the Tcherenisses of the Vyatka government promises to yield interesting results.

Among the new publ'cations of the Society we notice the following :-The Anthropology of Mordvinians, by W. N. Mairoff, is printing, and will appear in the eleventh volume of the Ethnographical Memoirs of the Society; the anthropological researches of K. S. Mereshkovsky in the Crimea, preliminary reports of which have appeared in the Izvestia, will soon be ready to print ; G. N. Potanin's work, "Sketches of NorthWestern Mongolia," being a report, in two volumes, of his first journey in Mongolia, is an important acquisition for the geography of Asia; the first volume contains abundance of valuable geographical information, and the second contains the ethnographical results, with twenty-six tables of drawings. Volumes iii. and iv. of this work, the third already being under press, will contain the results of the second journey of $M$. Potanin in Mongolia; the work of N. M. Prshevalsky, "Travels in the Deserts of Central Asia" will consist of six volumes, with more than I 20 drawings and maps, four volumes being devoted to the zoology, botany, and seology of these countries; the first volume is already finished by the author, as well as several parts of the following volumes:-An interesting map of Jungaria, drawn up by the Swedish Lieutenant Renat in the eighteenth century, after several months' imprisonment by Kalmuks, was published last year by A. S. Maksheef. Finally, the "Report" mentions also a series of pamphlets, in French, published for the Geographical Exhibition at Venice, which contains very good reviews of scientific work done in Russia in hydrography, zoo-geography, botanical geography, geology, and statistice during the last five years.

The ninth volume of the Memoirs of the Society for the Physico-Geographical Section contains an excellent work by A. W. Kaulbars on the delta of the Amu-daria-unhappily without the atlas of maps and drawings, which the Society was unable to publish. The tenth volume will contain the materials collected by the expedition of Karelin in 1830 , which are not yet published.

\section{PRELIMINARY NOTICE OF THE RESULTS} ACCOMPLISHED IN THE MANUFACTURE AND THEORY OF GRA TINGS FOR OPTICAL PURPOSES ${ }^{1}$

$\mathrm{IT}^{\mathrm{T}}$ is not many years since physicists considered that a spectroscope constructed of a large number of prisms was the best and only instrument for viewing the spectrum, where great power was required. These instruments were large ald expensive, so that few physicists could possess them. Prof. Young $w$ as the first to discover that some of the gratings of Mr. Rutherfurd showed more than any prism spectroscope which had then been constructed. But all the gratings which had been made up to that time were quite small, say I inch square, whereas the power of a grating in resolving the line of the spectrum increases with the size. Mr. Rutherfurd then attempted to make as large gratings as his machine would allow,

By Prof. H. A. Rowland. (Extract from Johns Hopkins University Circular, No. r6.) Communicated by the Author. 
and produced some which were nearly 2 inches square, though he was rarely successful above $1^{\frac{3}{4}}$ inches, having about 30,000 lines. These gratings were on speculum metal, and showed more of the spectsum than had ever before been seen, and have, in the hands of Young, Rutherfurd, Lockyer, and others, done much good work for science. Many mechanics in this country, and in France and Germany, have sought to equal Mr. Rutherfurd's gratings, but without success.

Under these circumstances, I have taken up the subject with the resources at command in the physical laboratory of the Johns Hopkins University.

One of the problems to be solved in making a machine is to make a perfect screw, and this, mechanics of all countries have sought to do for over a hundred years and have failed. On thinking over the matter, I devised a plan whose details I shall soon publish, by which I hope to make a practically perfect screw, and so important did the problem seem, that I immediately set Mr. Schneider, the instrument maker of the university, at work at one. The operation seemed so successful, that I immediately designed the remainder of the machine, and have now had the pleasure since Christmas of trying it. The screw is practically perfect, not by accident, but because of the new process for making it, and I have not yet been able to detect an error so great as I-100, oooth part of an inch at any part. Neither has it any appreciable periodic error. By means of this machine I have been able to make gratings with 43,000 lines to the inch, and have made a ruled surface with 160,000 lines on it, having about 29,000 lines to the inch. The capacity of the machine is to rule a surface $6 \frac{1}{4} \times 4 \frac{1}{4}$ inches, with any required number of lines to the inch, the number only being limited by the wear of the diamond. The machine can be set to almost any number of lines to the inch, but I have not hitherto attempted more than 43,000 lines to the inch. It ruled so perfectly at this figure that I see no reason to doubt that at least two or three times that number might be ruled in one inch, though it would be useless for making gratings.

All gratings hitherto made have been ruled on flat surfaces. Such gratings require a pair of telescopes for viewing the spectrum; these telescopes interfere with many experiments, absorbing the extremities of the spectrum strongly ; besides, two telescopes of sufficient size to use with 6 -inch gratings would be very expensive and clumsy affairs. In thinking over what would happen were the grating ruled on a surface not flat, I thought of a new method of attacking the problem, and soon found that if the lines were ruled on a spherical surface, the spectrum would be brought to a focus without any telescope. This discovery of concave gratings is important for many physical investigations, such as the photographing of the spectrum both in the ultra-violet and the ultra-red, the determination of the heating effect of the different rays, and the determination of the relative wave-lengths of the lines of the spectrum. Furthermore; it reduces the spectroscope to its simplest proportions, so that spectroscopes of the highest power may be made at a cost which can place them in the hands of all observers. With one of my new concave gratings I have been able to detect double lines in the spectrum which were never before seen.

The laws of the concave grating are very beantiful, on account of their simplicity, especially in the case where it will be used most. Draw the radius of curvature of the mirror to the centre of the mirror, and from its central point with a radius equal to half the radius of curvature draw a circle; this circle thus passes through the centre of curvature of the mirror, and touches the mirror at its centre. Now if the source of light is anywhere in this circle, the image of this source and the different orders of the spectra are all brought to focus on this circle. The word focus is hardly applicable to the case, however, for if the source of light is a point, the light is not brought to a single point on the circle, but is drawn out into a straight line with its length parallel to the axis of the circle. As the object is to see lines in the spectrum only, this fact is of little consequence, provided the slit, which is the source of light, is parallel to the axis of the circle. Indeed, it adds to the beauty of the spectra, as the horizontal lines due to dust in the slit are never present, as the dust has a different focal length from the lines of the spectrum. This action of the concave grating, however, somewhat impairs the light, especially of the higher orders, but the introduction of a cylindrical lens greatly obviates this inconvenience.

The beautiful simplicity of the fact that the line of foci of the different orders of the spectra are on the circle described above, leads immediately to a mechanical contrivance by which we can move from one spectrum to the next, and yet have the apparatus always in focus; for we have only to attach the slit, the eye-piece, and the grating to three arms of equal length, which are pivoted together at their other ends, and the conditions are satisfied. However we move the three arms, the spectra are always in focus. The most interesting case of this contrivance is when the bars carrying the eye-piece and grating are attached end to end, thus forming a diameter of the circle with the eye-piece at the centre of curvature of the mirror, and the rod carrying the slit alone movable. In this case the spectrum as viewed by the eye-piece is normal, and when a micrometer is used, the value of a division of its head in wave-lengths does not depend on the position of the slit, but is simply proportional to the order of the spectrum, so that it need be determined once only. Furthermore, if the eye-piece is replaced hy a photographic camera, the photographic spectrum is a normal one. The mechanical means of keeping the focus is especially important when investigating the ultra-violet and ultra-red portions of the solar spectrum.

Another important property of the concave grating is that all the superimposed spectra are in exactly the same focus. When viewing such superimposed spectra it is a most beautiful sight to see the lines appear coloured on a nearly white ground. By micrometric measurement of such superimposed spectra we have a most beautiful method of determining the relative wave-lengths of the different portions of the spectrum, which far exceeds in accuracy any other method yet devised. In working in the ultraviolet or ultra-red portions of the spectrum we can also focus on the superimposed spectrum, and so get the focus for the portion experimented on.

The fact that the light has to pass through no glass in the concave grating makes it important in the examination of the extremities of the spectrum where the glass might absorb very much. There is one important research in which the concave grating in its present form does not seem to be of much use, and that is in the examination of the solar protuberances ; an instrument can only be used for this purpose in which the dust in the slit and the lines of the spectrum are in focus at once. It might be possible to introduce a cylindrical lens in such a way as to obviate this difficulty. But for other work on the sun the concave grating will be found very useful. But its principal use will be to get the relative wavelengths of the lines of the spectrum, and so to map the spectrum; to divide lines of the spectrum which are very near together, and so to see as much as possible of the spectrum; to photograph the spectrum so that it shall be normal; to investigate the portions of the spectrum beyond the range of vision; and lastly to put in the hands of any physicist at a moderate cost such a powerful instrument as could only hitherto be purchased by wealthy inclividuals or institutions.

To give further information of what can be done in the way of gratings I will state the following particulars :-

The dividing engine can rule a space $6 \frac{1}{4}$ inches long, and $4 \frac{1}{4}$ inches wide. The lines, which can be $4 \frac{1}{4}$ inches long, do not depart from a straight line so much as I-I00, oooth of an inch, and the carriage moves forward in an equally straight line. The screw is practically perfect, and has been tested to $\mathrm{I}-\mathrm{I}$-oo, oooth of an inch, without showing error. Neither does it have any appreciable periodic error, and the periodic error due to the mounting and graduated head can be entirely eliminated by a suitable attachment. For showing the production of ghosts by a periodic error, such an error can be introduced to any reasonable amount. Every grating made by the machine is a good one, dividing the 1474 line with ease, but some are better than others. Rutherfurd's machine only made one in every four good, and only one in a long time which might be called first-class. One division of the head of the screw makes 14,438 lines to the inch. Any fraction of this number in which the numerator is not greater than say 20 or 30 can be ruled. Some exact numbers to the millimetre, such as $400,800,1200$, \& $c_{\text {, }}$, can also be ruled. For the finest definition either I 4,438 or 28,876 lines to the inch are recommended, the first for ordinary use, and the second for examining the extremities of the spectrum. Extremely brilliant gratings have been made with 43,314 lines to the inch, and there is little difficulty in ruling more if desired. The following show some results obtained :-

Flat grating, I inch square, 43,000 lines to the inch. Divides the 1474 line in the first spectrum.

Flat grating, $2 \times 3$ inches, 14,438 lines to the inch, total 43,314 . Divides 1474 in the first spectrum, the $\mathrm{E}$ line (Ang- 
ström $5269^{\circ}$ ) in the second, and is gond in the fourth and even fifth spectrum.

Flat grating, $2 \times 3$ inches, 1200 lines to one millimetre. Shows very many more lines in the $B$ and $A$ groups than were ever before seen.

Flat grating, $2 \times 3^{\frac{1}{4}}$ inches, 14,438 lines to the inch. This has most wonderful brilliancy in one of the first spectra, so that $I$ have seen the $Z$ line, wave-length 8420 (see Abney's map of the ultra-red region), and determined its wave-length roughly, and have seen much further below the $\mathrm{A}$ line than the $\mathrm{B}$ line is above the $A$ line. The same may be said of the violet end of the spectrum. But such gratings are only obtained by accident.

Concave grating, $2 \times 3$ inches, 7 feet radius of curvature, $48 \mathrm{I} 8$ lines to the inch. The coincidences of the spectra can be observed to the tenth or twelfth spectrum.

Concave grating, $2 \times 3$ inches, $14,43^{8}$ lines to the inch, radius of curvature 8 feet. Divides the 1474 line in the first spectrum, the $\mathrm{E}$ line in the second, and is good in the third or fourth.

Concave grating, $3 \times 5 \frac{1}{2}$ inches, $r 7$ feet.radius of curvature, 28,876 lines to the inch, and thus nearly 160,000 lines in all. This shows more in the first spectrum than was ever seen before. Divides 1474 and E vely widely, and shows the stronger component of Angström 5275 double. Second spectrum not tried.

Concave grating, $4 \times 5^{\frac{3}{4}}$ inches, 36 ro lines to the inch, radius of curvature 5 feet 4 inches. This grating was made for Prof. Langley's experiments on the ultra-red portion of the spectrum, and was thus made very bright in the first spectrum. The definition seems to be very fine, notwithstanding the short focus, and divides the $\mathbf{1 4 7 4}$ line with ease. But it is difficult to rule so concave a grating, as the diamond marks differently on the different parts of the plate.

These give illustrations of the results accomplished, but of course many other experiments have been made. I have not yet been able to decide whether the definition of the concave grating fully comes up to that of a flat grating, but it evidently does so very nearly.

\section{UNIVERSITY AND EDUCATIONAL INTELLIGENCE}

CAMBRIDGE.-The following awards have been made at St. John's College for proficiency in natural science :-Foundation Scholarships to Bateson, Goodman; Exhibitions to Edmunds, Love, T. Roberts (already scholars), and to Acton, Andrews, Clementson. T. Roberts also received a Wright's Prize, with augmentation of scholarship to $\mathrm{IOO}$. for the year. In the Open Exhibition Examination at Easter, H. Stroud (Owens College) was awarded a a Foundation Scholarship of 100, and Fuller (Perse School, Cambridge), 50l. for three years.

In the long list of lectures on Natural Scjence for the ensuing academical year, lately published, we note as new courses or features of special interest, $\mathrm{Mr}$. Shaw's lectures on some Applications: of the Higher Mathematics to Physics (Michelmas Term); Dr. Roberts's lectures on Physiography (Michaelmas Term); Prof. Hughes's Course of Dynamical Geology (Lent Term) ; Dr. Vines's complete course of advanced Botanical Study, extending through the year; Prof. Newton's lectures on the Evidence of Evolution in the Animal Kingdom, in the Michaelmas Term, and on the Geographical Distribution of Animals, in the Easter Term ; and Prof. Balfour's announcement of his lectures and practical work, as Professor of Animal Morphology.

The annual report of the Botanic Gardens Syndicate details work done in improving the Gardens, and amongst valuable additions to the collection, the Tonga plant, recently introduced from the Fiji Islands. A special collection of medical plants has been formed, which already contains the most importan hardy plants, and some of considerable rarity. About 8000 labels have been written during the year.

With regard to the recent Mathematical Tripos (in which Messrs. Welsh of Jesus College, and Turner of Trinity College, were respectively Senior and Second Wranglers), although the twenty-nine Wranglers may enter for a further advanced examination in January next, they are by no means compelled to do so. The examination, so far as it has already proceeded, includes very many of the subjects of the old Mathematical Tripos, and we anticipate that unless the colleges decline to elect to Fellowships Wranglers who do not proceed to the higher examination, many will rest content with the test already undergone. The recent talk about the "abolition of the Senior Wrangler" has not a very valid basis.

THE eighth annual meeting of the Yorkshire College was held at Leeds on Saturday, Sir Edward Baines in the chair. Prof. Marshall, the principal, made a satisfactory report, and a resolution of the council was confirmed to proceed with the completion of the new college buildings. On the proposition of the Mayor of Leeds (Alderman Tatham) it was resolved that, in memory of the late Lord F. Cavendish, M.P., the late president of the college, who for twelve years had been one of its foremost promoters, a fund be established for the endowment ot a Cavendish Professorship of Physics or for such other purpose as the council should deem best.

\section{SCIENTIFIC SERIALS}

Notes from the Leyden Museum, vol. iv. No. 2, April, 1882, contain : On American Diptera, by F. M. van der Wulf,-On new species of Lycidæ, Lampyridæ, and Telephoridæ, and on a new Sumatran species of Callimerus, by Rev. H. S. Gorham.On new species of Pedilidæ and Anthicidæ, and on a new African species of Hister, by $S$. de Marseul.-On the Holothurians in the Leyden Museum, by Dr. H. Ludwig.-On some British Indian reptiles and amphibia, by Dr. A. Hubrecht.-On the Pselaphidæ and Scydmænidæ of the Sunda Islands by Dr. L. W. Schaufuss.-Description of a new species of Apogonia, by Dr. D. Sharp. -On a new species of Pantolamprus from Liberia, by Dr. E. Candèze.

Bulletin de la Soc. Imp. des Naturalistes de Moscou, tome lvi. No, 3,1882 , contains; V. Kiprijanoff, on fish remains in the Siwerischen Osteoliths (2 plates).-Dr. Max Schmidt, on Bolborhynchus monachus. - Prof. K. Lindeman, on Coleophora tritici, a new injurious Russian insect. -Dr. J. v. Bedriaga.-On the A'mphibia and Reptiles of Greenland.-F. v. Thumen, contributions to the fungal-flora of Siberia. -N. Vischniakoff, on the Ammonites distractus of Quensted.-Prof. Bredichen, report on the tails of comets I88I $b$ and $c$.-Dr. E. Kern, on a new milk ferment from the Caucasus ( 2 plates). -Th. A. Sludski, on two inequalities taking place in the movement of the solar system (in Russian).-A. Becker, journey to Southern Daguestan.-M. Menzbier, comparative review of the ornithological fauna of Moscow and Toula.-A. Regel, Correspondence.

Zeitschrift für wissenschaftliche Zoologie, vol. xxxvi., part 4, I882, contains J. Brock, on the anatomy and systematic position of the Cephalopoda (with plates 34 to 37 ). -O. Katz, contribution to a knowledge of the tegumentary system of the pouch and its several accompanying organs in the marsupials (with plates $3^{8-40)}$. - R. Rössler, contribution to the anatomy of the Phalangidæ (with plates $4 \mathbf{I}$ and 42 ).

Archives des Sciences Physiques et Naturelles, May 15.-Study on the chemical composition of albuminoid substances (continued), by A. Danilewsky.-Mean diurnal heights of Lake Leman, at Secheron, from 1874 to 1881 , by P. Plantamour.The rheolyser, by $\mathbf{E}$. Hartmann.-Darwin considered as regards the causes of his success and the importance of his works, by Alph. de Candolle.

Sitzungsberichte und Abhandlungen der naturwissenschaftlichen Gesellschaft Isis in Dresden, July to December, 188r.-On some lime-spar crystals, by A. Pungold.-Flora of Dresden and its environs, by C. F. Schulze.-On the oldest traces of fossil plants in Saxony, by H. B. Geinitz.--On the progress of Geological researches in North America, by the same.-On the occurrence of Cenomanian petrefactions at Dohne, by J. v. Deichmüller. On the occurrence of the Riesengebirge races of Pinus Montana, Müll., in the Saxon-Bohemian Oberlausitz, by O. Drude.

\section{SOCIETIES AND ACADEMIES LONDON}

Royal Society, June 15.- "On an Arrangement of the Electric Arc for the Study of the Radiation of Vapours, together with the Preliminary Results." By Professors Liveing and Dewar.

By the arrangement described, the authors are able to make observations as the temperature rises and as it falls, and so to trace the influence of temperature in many cases in which the extent of that influence was before doubtful. The temperature 